\title{
Body mass index and circulating oestrone sulphate in women treated with adjuvant letrozole
}

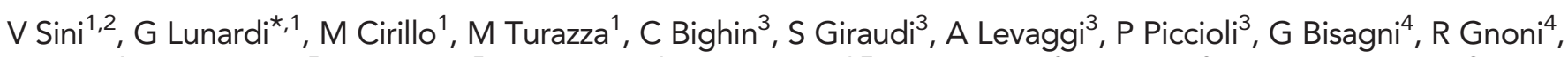

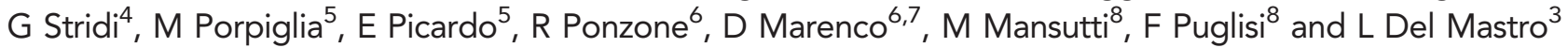

${ }^{1}$ Medical Oncology Unit, Sacro Cuore Don Calabria Hospital, Via Sempreboni, 5, 37024 Negrar (Verona), Italy; ${ }^{2}$ Oncology Unit, Surgical and Medical Department of Clinical Sciences, Sant'Andrea Hospital, via di Grottarossa, 1035, 00189 Rome, Italy; ${ }^{3}$ Medical Oncology Department, IRCSS AOU San Martino, IST, L.go R. Benzi, 10, 16132 Genoa, Italy; ${ }^{4}$ Department of Oncology, Azienda Ospedaliera ASMN, viale Risorgimento, 80, 42123 Reggio Emilia, Italy; ${ }^{5}$ University Department of Gynecology and Obstetrics, S.Anna Hospital, Corso Spezia, 60, 10126 Turin, Italy; ${ }^{6}$ Gynecological Oncology, Institute for Cancer Research and Treatment, Strada Provinciale 142, Km 3.95, 10060 Candiolo (Turin), Italy; ${ }^{7}$ Gynecology and Obstetrics, Santa Croce Hospital, Piazza Amedeo Ferdinando, 3, 10024 Moncalieri (Turin), Italy and ${ }^{8}$ Oncology Department, University Hospital of Udine, Piazzale Santa Maria della Misericordia, 15, 33100 Udine, Italy

Background: Obesity is an independent adverse prognostic factor in early breast cancer patients, but it is still controversial whether obesity may affect adjuvant endocrine therapy efficacy. The aim of our study (ancillary to the two clinical trials Gruppo Italiano Mammella (GIM)4 and GIM5) was to investigate whether the circulating oestrogen levels during treatment with the aromatase inhibitor letrozole are related to body mass index (BMI) in postmenopausal women with breast cancer.

Methods: Plasma concentration of oestrone sulphate (ES) was evaluated by radioimmunoassay in 370 patients. Plasma samples were obtained after at least 6 weeks of letrozole therapy (steady-state time). Patients were divided into four groups according to BMI. Differences among the geometric means (by ANOVA and ANCOVA) and correlation (by Spearman's rho) between the ES levels and BMI were assessed.

Results: Picomolar geometric mean values (95\% confidence interval, $n=$ patients) of circulating ES during letrozole were 58.6 $(51.0-67.2, n=150)$ when BMl was $<25.0 \mathrm{~kg} \mathrm{~m}^{-2} ; 65.6(57.8-74.6, n=154)$ when $25.0-29.9 \mathrm{~kg} \mathrm{~m}^{-2} ; 59.3(47.1-74.6, n=50)$ when $30.0-34.9 \mathrm{~kg} \mathrm{~m}^{-2}$; and $43.3(23.0-81.7, n=16)$ when $\geqslant 35.0 \mathrm{~kg} \mathrm{~m}^{-2}$. No statistically significant difference in terms of ES levels among groups and no correlation with BMI were observed.

Conclusions: Body mass index does not seem to affect circulating oestrogen levels in letrozole-treated patients.

High body mass index (BMI) is associated with a significant increased incidence of postmenopausal breast cancer (Carpenter et al, 2003; Eliassen et al, 2006; Reeves et al, 2007; Vrieling et al, 2010; Key et al, 2011) and with an increased risk of breast cancer recurrence and mortality in patients with a previous diagnosis of breast cancer (Ewertz et al, 2011; Sparano et al, 2012).

Obese postmenopausal women may have an increased oestrogen synthesis, mediated by the enzyme aromatase (Miller, 2006), which leads to higher levels of circulating oestrogens compared with women

\footnotetext{
*Correspondence: Dr G Lunardi; E-mail: gianluigi.lunardi@sacrocuore.it

This work is dedicated to the late Marco Venturini,outstanding clinician, clinical researcher and teacher, who gave a major contribution in concept and design of GIM4 and GIM5 clinical trials.
}

Received 5 September 2013; revised 3 December 2013; accepted 17 December 2013; published online 21 January 2014

(c) 2014 Cancer Research UK. All rights reserved 0007 - 0920/14 
of similar age but with normal BMI (Judd et al, 1974). The high levels of circulating oestrogens could explain the inferior outcome observed in obese hormone receptor-positive breast cancer women (Sparano et al, 2012) compared with non-obese. While obesity at diagnosis is known to be an independent adverse prognostic factor in early-stage breast cancer, it is still unknown whether obesity may affect the efficacy of adjuvant endocrine therapy.

The association between clinical outcome and BMI in both advanced and early breast cancer treated with aromatase inhibitors is still controversial (Schmid et al, 2000; Michaud et al, 2002; Sestak et al, 2010; Seynaeve et al 2010; Pfeiler et al, 2011; Ewertz et al, 2012; Wolters et al, 2012). In advanced breast cancer, it was reported that obese patients benefited significantly less from letrozole treatment than thin women (Schmid et al, 2000). On the other hand, Michaud et al (2002) found that the efficacy of anastrozole did not depend on BMI. In the adjuvant setting, treatment with anastrozole was associated with a lower recurrence rate as compared with tamoxifen, regardless of the BMI, but its benefit was greater in thinner women (Sestak et al, 2010). The subgroup analysis of the German BRENDA cohort showed a significantly shorter recurrence-free survival in postmenopausal obese patients, who tended to benefit more from tamoxifen than from aromatase inhibitors (Wolters et al, 2012).

On the other hand, data from the Tamoxifen Exemestane Adjuvant Multinational (TEAM) trial showed no differences in disease recurrences between obese women treated with tamoxifen and those treated with exemestane (Seynaeve et al, 2010), and results from the Breast International Group 1-98 Trial indicated that letrozole clinical efficacy was not associated with BMI (Ewertz et al, 2012).

Here, we investigate the correlation between BMI and the activity (evaluated through plasma concentration of oestrone sulphate (ES)) of the aromatase inhibitor letrozole in early breast cancer postmenopausal women, who were in adjuvant endocrine treatment.

\section{PATIENTS AND METHODS}

Patients. Postmenopausal women with radically resected early breast cancer (defined as tumours that are T1-2, N0-1, M0 according to TNM staging system), oestrogen receptor (ER)-positive and/or progesterone receptor (PR)-positive (considering positive every values of $\geqslant 1 \%$ ) were enrolled into this study between 2005 and 2008.

Main inclusion criteria for the Gruppo Italiano Mammella (GIM)4 and GIM5 studies were

(A) Stage I-III, histologically proven ER-positive and/or PRpositive breast cancer;

(B) Definitive surgical treatment (either mastectomy or breast conserving surgery) and axillary or sentinel node dissection;

(C) Previous adjuvant hormonal therapy with tamoxifen for 2-3 years (GIM4 study) or at least $4 \frac{1}{2}$ years and not more than 6 years (GIM5 study). Tamoxifen had to be completed not more than 6 months before study entry;

(D) Postmenopausal status defined as: (i) age $>55$ years with cessation of menses or (ii) age $<55$ years but not spontaneous menses for $\geqslant 1$ year, or (iii) age $<55$ years and spontaneous menses within the previous 12 months, but currently amenorrheic (e.g., spontaneous, or secondary to hysterectomy), and with postmenopausal gonadotropin levels (luteinising hormone and follicle-stimulating hormone levels $>40 \mathrm{IUl}^{-1}$ ) and postmenopausal oestradiol levels $\left(<5 \mathrm{ng} \mathrm{dl}^{-1}\right)$ or according to the definition of 'postmenopausal range' for the laboratory involved;

(E) Eastern Cooperative Oncology Group (ECOG) Performance Status $\leqslant 2$;

(F) Adequate bone marrow, liver and kidney function.
Study design. This study is a part of two prospective, multicentre, not blinded, studies of adjuvant hormonal therapy for early breast cancer patients: GIM4 and GIM5 studies.

The GIM4 study (LEAD study, LEtrozole Adjuvant Duration) is a phase III, multicentre randomised study that evaluates the optimal duration of adjuvant hormonal therapy with letrozole in postmenopausal women diagnosed with early breast cancer treated with 2-3 years of tamoxifen: after 2-3 years of tamoxifen treatment, patients were randomised either to receive letrozole up to a total duration of the endocrine treatment of 5 years or to receive letrozole for an additional 5 years regardless of the duration of the previous tamoxifen treatment (Clinical trial.gov identifier: NCT01064635).

The GIM5 study (CYPLEC study) is a multicentre, prospective, non-randomised study of adjuvant hormonal therapy with letrozole in women diagnosed with early breast cancer patients after $4 \frac{1}{2}$ to 6 years of tamoxifen that provides a genetic analysis of CYP19 gene, plasma evaluation of letrozole and ES before and during letrozole treatment (EudraCT n. 2005-001213-18) (Lunardi et al, 2013).

A subgroup of patients from five centres, participating in both GIM4 and GIM5 studies, were enrolled in this ancillary study. The aim was to evaluate the association between ES levels and BMI in postmenopausal women diagnosed with breast cancer receiving treatment with letrozole (Femara; Novartis, Basel, Switzerland) $2.5 \mathrm{mg}$ daily.

For this ancillary study on ES levels and obesity, patients had to be on treatment with letrozole for at least 6 weeks (i.e., at the time of letrozole steady state).

The studies were approved according to Italian national regulations. Written informed consent was obtained from each subject before the beginning of protocol-specific procedures, according to institutional procedures and to the declaration of Helsinki. Each patient received letrozole $2.5 \mathrm{mg}$ daily, provided by medical oncology departments. Physical examination and compliance (patients were questioned to confirm compliance and the number of tablets were accounted for) were assessed every 3 months.

Hormone measurements. The use of plasma oestrogens (oestradiol and oestrone) to evaluate the activity of aromatase inhibitors is hampered by technical difficulties in measuring very low postmenopausal oestrogen levels (Geisler et al, 2002, 2008; Dixon et al, 2008). This is a minor problem with ES, whose levels are measurable by highly sensitive assay methods also in postmenopausal women. Plasma ES is produced by sulfatation of circulating oestrone and the levels of oestradiol, oestrone and ES are in equilibrium (Lønning and Ekse, 1995).

Samples were collected in five Italian medical oncology departments. Medical oncologists of each centre were adequately instructed about sample collection and storage.

Blood samples for hormone measurements were collected in vials containing sodium EDTA between 0800 and $1000 \mathrm{~h}$ to avoid circadian variations. Blood samples were collected after no less than 6 weeks (i.e., at the time of letrozole steady state; Lønning et al, 2003), from the beginning of letrozole treatment. Plasma samples were separated by centrifugation and stored at $-80^{\circ} \mathrm{C}$ until analysis that was performed, on average, within 6 months.

Estrone sulphate levels were determined by a commercially available (DSL-5400 Diagnostic Systems Laboratories Inc., Webster, TX, USA) radioimmunoassay (RIA) after a nonchromatographic procedure to eliminate interferences from dehydroepiandrosterone sulfate (DHEAS) (Brind et al, 1990) according to a validated method (Lunardi et al, 2013) described previously.

Assay sensitivity was $14 \mathrm{pMl}^{-1}(\mathrm{CV}<14 \%)$ and was calculated by the instrument (gamma-scintillation counter Cobra II Autogamma; Canberra Packard, Central Europe GmbH, Schwadorf, Austria). 
Values below this limit were used for calculation of the means and they were assigned half the value of the lower limit of quantification (Hornung and Reed, 1990).

BMI definition. Body mass index was calculated by the formula: weight/height ${ }^{2}\left(\mathrm{~kg} \mathrm{~m}^{-2}\right)$. According to the World Health Organization classification (http://www.who.int/bmi/index.jsp; 3 August 2012), patients were divided into four groups according to their BMI value: lower than 25.0; from 25.0 to 29.9; from 30.0 to 34.9 and higher than 35.0. In accordance with the World Health Organization, a BMI of greater than $25.0 \mathrm{~kg} \mathrm{~m}^{-2}$ indicates overweight, a BMI from 30.0 to $34.9 \mathrm{~kg} \mathrm{~m}^{-2}$ indicates obesity and a value of greater than $35.0 \mathrm{~kg} \mathrm{~m}^{-2}$ indicates severe obesity.

Statistical methods. Plasma levels of ES were evaluated through a logarithmic normal distribution (ln) (Lønning et al, 1995), and these values of ES were utilised for statistical analyses. Geometric means and 95\% confidence intervals were used as summary measures.

To assess the difference between the geometric means, the ANOVA and the ANCOVA (adjusted for parent study, study centre, patient's age and length of time on letrozole) were applied.

The relationship between BMI and plasma oestrogen levels was assessed by Spearman's rank correlation. The software STATA/IC 11.1 (StataCorp LP, College Station, TX, USA) for Windows was utilised for statistics. A two-sided value of $P<0.05$ was considered as statistically significant.

\section{RESULTS}

Oestrone sulphate plasma levels and BMI values were evaluated in 370 patients treated with letrozole for at least 6 weeks, that is, at the time of letrozole steady state (Lønning et al, 2003), and enrolled in GIM4 (194 patients) and GIM5 (176 patients) studies. The individual values of circulating ES in respect with BMI are shown in Figure 1. Patient characteristics are reported in Table 1.

Values of BMI were the following: BMI $<25.0 \mathrm{~kg} \mathrm{~m}^{-2}$ in 150 patients (40.5\%); BMI from 25.0 to $29.9 \mathrm{~kg} \mathrm{~m}^{-2}$ in 154 (41.6\%) patients; BMI from 30.0 to $34.9 \mathrm{~kg} \mathrm{~m}^{-2}$ in 50 (13.5\%) patients and $\mathrm{BMI} \geqslant 35.0 \mathrm{~kg} \mathrm{~m}^{-2}$ in $16(4.3 \%)$ patients.

Median age of patients was 60 (range: $34-84$ years). No differences between the four groups were observed: median age 56 (range 34-78), 62 (44-84), 63 (48-78) and 57 (47-78), from the lower to the higher BMI group, respectively. Five patients in BMI group $<25.0 \mathrm{~kg} \mathrm{~m}^{-2}$ and two in group $25.0-29.9 \mathrm{~kg} \mathrm{~m}^{-2}$ resulted under the age of 45 years.

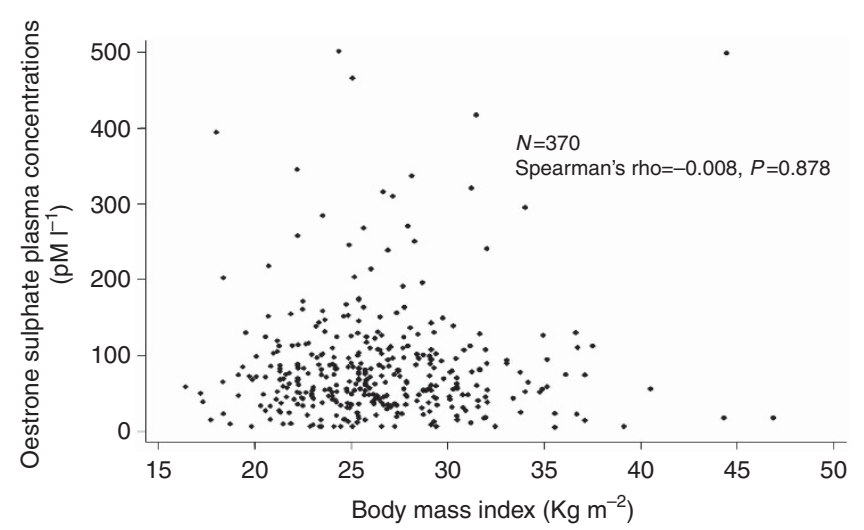

Figure 1. Scatter plot of plasma oestrone sulphate circulating concentrations $\left(\mathrm{pMI}^{-1}\right)$ according to body mass index $\left(\mathrm{kg} \mathrm{m}^{-2}\right)$, in 370 women treated with letrozole.
Median duration of treatment with letrozole was 53 weeks (range: 6-218 weeks). There was no difference in timing of plasma sample collection between the different BMI groups: 52 (6-218), 54 (6-197), 52 (6-213) and 55 (6-187) weeks.

Plasma ES geometric means (95\% confidence interval) were $58.6 \mathrm{pMl}^{-1}(51.0-67.2)$ in the group of patients with BMI $<25.0 \mathrm{~kg} \mathrm{~m}^{-2}, 65.6 \mathrm{pMl}^{-1}(57.8-74.6)$ in patients from 25.0 to $29.9 \mathrm{~kg} \mathrm{~m}^{-2}, 59.3 \mathrm{pMl}^{-1}(47.1-74.6)$ in patients from 30.0 to $34.9 \mathrm{~kg} \mathrm{~m}^{-2}$ and $43.3 \mathrm{pMl}^{-1}(23.0-81.7)$ in patients with BMI higher than $35.0 \mathrm{~kg} \mathrm{~m}^{-2}$ (Table 2).

Plasma ES levels resulted below the sensitivity limit in thirteen (3\%) patients: six, five, one and one, from the lower to the higher BMI group, respectively.

Oestrogenic concentrations were similar in the different groups of BMI. The ANOVA $(P=0.244)$ and ANCOVA $(P>0.102)$ tests did not show any statistically significant difference between the geometric means observed in the different BMI groups.

No correlation between BMI and circulating ES concentration was found by Spearman's rank correlation test (Spearman's rho = $-0.008, P=0.878)$.

\section{DISCUSSION}

Our study evaluated the circulating concentrations of ES during letrozole treatment at the standard dose of $2.5 \mathrm{mgday}^{-1}$ in patients with different BMI.

Oestrone sulphate levels were evaluated as a surrogate of circulating oestrogens. Oestrogenic concentrations were similar between the different groups of BMI. No correlations were observed between BMI and ES plasma levels during letrozole treatment.

Letrozole plasma concentrations were not assessed to evaluate compliance, but patients were questioned to confirm compliance and the number of tablets was accounted for at each follow-up visit (assessed every 3 months).

Three recent publications evaluated the influence of BMI on aromatase inhibitors activity.

Diorio et al (2012) compared oestradiol levels in postmenopausal women treated with anastrozole, letrozole or exemestane. Women were divided according to their BMI (30 patients $<25 \mathrm{~kg} \mathrm{~m}^{-2}$ and 30 patients $>30 \mathrm{~kg} \mathrm{~m}^{-2}$ ) and matched for age. According to results of us, no association was observed between oestradiol plasma levels and BMI in women treated with aromatase inhibitors. Oestradiol levels were similar in thin and obese women treated with aromatase inhibitors $(P=0.76)$.

Similar data were reported in a very recent paper (Pfeiler et al, 2013); after 3 months of aromatase inhibitors treatment, oestradiol levels of 28 patients with BMI $\geqslant 30.0 \mathrm{~kg} \mathrm{~m}^{-2}$ were not significantly higher compared with 40 patients with BMI $<29.9 \mathrm{~kg} \mathrm{~m}^{-2}$ $(P=0.1)$.

Folkerd et al (2012) evaluated plasma oestradiol and ES levels in a crossover study (ALIQUOT) on 44 postmenopausal patients treated with anastrozole ( $1 \mathrm{mg}$ per day) for 3 months followed by letrozole ( $2.5 \mathrm{mg}$ per day) for 3 months or the opposite sequence. They found a weak correlation between BMI and circulating levels of oestrogens in patients treated with letrozole $(r=0.35 ; P=0.013$, and $r=0.30 ; P=0.035$ for oestradiol and ES, respectively) but no correlation in the same group when treated with anastrozole (Folkerd et al, 2012). Mean ES concentrations, during letrozole treatment, were lower in the $<25 \mathrm{~kg} \mathrm{~m}^{-2}$ group $\left(13 \mathrm{pMl}^{-1}\right)$, but similar among 25-29, 30-35 and > 35 BMI groups (mean 22, 35 and $25 \mathrm{pMl}^{-1}$, respectively). When women received anastrozole mean oestrogen sulfate concentrations were similar among all groups (mean 44, 62, 66 and $68 \mathrm{pMl}^{-1}$, respectively). Noteworthy, in the study of Folkerd, in all groups of patients the absolute levels 


\begin{tabular}{|c|c|c|c|c|c|}
\hline Characteristics & $\begin{array}{c}\text { Global } \\
(\mathbf{N}=370)\end{array}$ & $\begin{array}{c}\mathrm{BMI}<25.0 \\
(N=150)\end{array}$ & $\begin{array}{c}\text { BMI 25.0-29.9 } \\
\quad(\boldsymbol{N}=154)\end{array}$ & $\begin{array}{l}\text { BMI 30.0-34.9 } \\
\quad(N=50)\end{array}$ & $\begin{aligned} \mathrm{BMI} & \geqslant 35.0 \\
(\mathrm{~N} & =16)\end{aligned}$ \\
\hline $\begin{array}{l}\text { Median age, years (range) } \\
\text { Mean weight, } \mathrm{kg} \text { (s.d.) } \\
\text { Mean height, } \mathrm{m} \text { (s.d.) } \\
\text { Mean BMI, } \mathrm{kg} \mathrm{m}^{-2} \text { (s.d.) }\end{array}$ & $\begin{array}{l}60(34-84) \\
68(11) \\
1.61(0.06) \\
26.3(4.4)\end{array}$ & $\begin{array}{l}56(34-78) \\
59(6) \\
1.62(0.06) \\
22.4(1.9)\end{array}$ & $\begin{array}{l}62(44-84) \\
70(6) \\
1.61(0.06) \\
27.1(1.4)\end{array}$ & $\begin{array}{l}63(48-78) \\
80(8) \\
1.59(0.06) \\
31.7(1.4)\end{array}$ & $\begin{array}{l}57(47-78) \\
95(13) \\
1.57(0.06) \\
38.4(3.7)\end{array}$ \\
\hline \multicolumn{6}{|l|}{ Age, $N$ (\%) } \\
\hline $\begin{array}{l}<50 \\
50-55 \\
>55 \\
\text { Median Let duration, weeks (range) }\end{array}$ & $\begin{array}{l}37(10) \\
75(20) \\
258(70) \\
53(6-218)\end{array}$ & $\begin{array}{l}23(15) \\
41(27) \\
86(57) \\
52(6-218)\end{array}$ & $\begin{aligned} 9 & (6) \\
25 & (16) \\
120 & (78) \\
54 & (6-197)\end{aligned}$ & $\begin{aligned} & 2(4) \\
& 5(10) \\
& 43(86) \\
& 52(6-213)\end{aligned}$ & $\begin{array}{c}3(19) \\
4(25) \\
9(56) \\
55(6-187)\end{array}$ \\
\hline \multicolumn{6}{|l|}{ Clinical trial, $\mathbf{N}(\%)$} \\
\hline $\begin{array}{l}\text { GIM4 } \\
\text { GIM5 }\end{array}$ & $\begin{array}{l}194(52) \\
176(48)\end{array}$ & $\begin{array}{l}83(55) \\
67(45)\end{array}$ & $\begin{array}{l}79(51) \\
75(49)\end{array}$ & $\begin{array}{l}24(48) \\
26(52)\end{array}$ & $\begin{array}{l}8(50) \\
8(50)\end{array}$ \\
\hline
\end{tabular}

Table 2. Plasma oestrone sulphate geometric means

\begin{tabular}{|c|c|c|c|c|}
\hline $\begin{array}{l}\text { Body mass } \\
\text { index }\left(\mathrm{kg} \mathrm{m}^{-2}\right)\end{array}$ & $\begin{array}{l}\text { Number } \\
\text { of patients }\end{array}$ & $\%$ & $\begin{array}{c}\text { Oestrone } \\
\text { Sulphate } \\
\text { geometric } \\
\text { mean } \\
\left(\mathrm{pMI} \mathrm{I}^{-1}\right)\end{array}$ & $\begin{array}{c}95 \% \\
\text { Confidence } \\
\text { interval }\end{array}$ \\
\hline$<25.0$ & 150 & 40.5 & 58.6 & $51.0-67.2$ \\
\hline $25.0-29.9$ & 154 & 41.6 & 65.6 & $57.8-74.6$ \\
\hline $30.0-34.9$ & 50 & 13.5 & 59.3 & $47.1-74.6$ \\
\hline$\geqslant 35.0$ & 16 & 4.3 & 43.3 & $23.0-81.7$ \\
\hline
\end{tabular}

of both oestradiol and ES were much lower during aromatase inhibitor treatment than pretreatment levels. The rates of oestrogen suppression achieved with aromatase inhibitors in obese patients were very high (about 98\% for letrozole and 96\% for anastrozole) and similar to those obtained in thin patients (Ligibel and Winer, 2012), thus suggesting that higher than standard doses of these drugs in obese women are unlikely to lead to a more complete oestrogen suppression.

In our study, we evaluated oestrogen synthesis by the assessment of ES levels because they can be considered as a good surrogate of circulating oestrogens (Lønning and Ekse, 1995). In fact, oestradiol and oestrone plasma levels in postmenopausal women treated with aromatase inhibitors could be very low and undetectable (Geisler et al, 2002, 2008; Dixon et al, 2008), and a major problem in evaluating the biochemical activity of aromatase inhibitors in vivo is the assay method sensitivity.

Despite the potential limitation of the oestrogen level assay methods, our study, the study of Diorio et al and that of Pfeiler et al suggest that the potential impact of obesity on recurrence risk in women treated with aromatase inhibitors may not be related to an incomplete aromatase inhibition in obese women. Because in postmenopausal women the extent of aromatisation of androgens to oestrogens is a function of body weight (Edman et al, 1978; Edman and MacDonald, 1978), it was hypothesised that in overweight/obese women extraglandular aromatisation from adipose tissue is not suppressed enough by the standard dose of aromatase inhibitors with a consequent reduced activity of these drugs in obese women. Such a hypothesis is not supported by our data.

Data from studies evaluating the relationship between clinical outcome and BMI in both advanced and early breast cancer treated with aromatase inhibitor-based endocrine therapy are conflicting. In advanced breast cancer, Schmid et al (2000) found that obese patients treated with letrozole benefited significantly less from letrozole treatment than those with a lower BMI. In contrast, Michaud et al (2002) found that the efficacy of anastrozole did not depend on BMI.

In the adjuvant setting, Sestak et al (2010) investigated the role of BMI in the relative benefit of the adjuvant treatment with anastrozole or tamoxifen within the randomised double-blind Arimidex, Tamoxifen Alone or in Combination (ATAC) trial. After a median follow-up of 100 months, women obese at baseline had a significantly higher rate of breast cancer recurrences compared with non-obese women. The treatment with anastrozole was associated with a lower recurrence rate as compared with tamoxifen, regardless of the BMI, but its benefit was greater in thinner women (Sestak et al, 2010).

The subgroup analysis of the German BRENDA cohort investigated the correlation between BMI, recurrence-free survival and adjuvant endocrine therapy. A significantly shorter recurrence-free survival was seen in postmenopausal obese patients and hormone receptor-positive postmenopausal patients with normal or intermediate weight showed a statistically non-significant trend towards a survival benefit for aromatase inhibitors compared with tamoxifen, while obese patients tended to benefit more from tamoxifen (Wolters et al, 2012).

In contrast to previous reports, data from the TEAM trial showed no differences in disease recurrences between obese women treated with tamoxifen and those treated with exemestane (Seynaeve et al, 2010). Finally, recent data from the Breast International Group 1-98 Trial indicated that, even though obesity was an independent adverse prognostic factor for death after breast cancer, letrozole clinical efficacy was not associated with BMI (Ewertz et al, 2012).

The relationship between obesity and breast cancer is quite complex. A recent meta-analysis demonstrated that the association between obesity and poor overall survival is similar in hormone receptor-positive and hormone receptor-negative breast cancer patients (Niraula et al, 2012). Pathways not related to sex hormones (insulin, Goodwin et al, 2002 or related proteins, Duggan et al, 2011; Irwin et al, 2011; insulin-like growth factor signalling pathways, Renehan et al, 2006; adipokines or growth factors secreted by adipose stromal cells from endogenous adipose tissue, Zhang et al, 2012) may contribute to the effects of obesity on breast cancer clinical outcomes. 
In conclusion, our results show that increased BMI does not affect the ability of letrozole in suppressing endogenous levels of oestrogens, evaluated by ES assessment. Mechanisms other than the high oestrogen synthesis could contribute to the poorer prognosis observed in obese breast cancer patients.

\section{ACKNOWLEDGEMENTS}

We gratefully acknowledge Marco Venturini, for his major contribution in concept and design of GIM4 and GIM5 clinical trials, and all the participants of the Gruppo Italiano Mammella. This work was partially supported by a grant of Italian Ministero della Salute 'Progetto Oncologico di medicina molecolare: I tumori femminili', 2008. The author disclosed receipt of the following financial support for the research, authorship, and/or publication of this article: Valentina Sini is financed through the $\mathrm{PhD}$ University Grant Program 'Clinical and Experimental Research Methodologies in Oncology' provided by the Faculty of Medicine and Psychology, 'Sapienza' University of Rome.

\section{CONFLICT OF INTEREST}

The authors declare no conflict of interest.

\section{REFERENCES}

Brind JL, Chervinsky K, Völgelman JH, Orentreich N (1990)

Radioimmunoassay of estrone sulfate in the serum of normal men after a non-chromatographic procedure that eliminates interference from dehydroepiandrosterone sulphate. Steroids 55: 32-35.

Carpenter CL, Ross RK, Paganini-Hill A, Bernstein L (2003) Effect of family history, obesity and exercise on breast cancer risk among postmenopausal women. Int J Cancer 106: 96-102.

Diorio C, Lemieux J, Provencher L, Hogue JC, Vachon E (2012) Aromatase inhibitors in obese breast cancer patients are not associated with increased plasma estradiol levels. Breast Cancer Res Treat 136: 573-579.

Dixon JM, Renshaw L, Young O, Murray J, Macaskill EJ, McHugh M, Folkerd E, Cameron DA, A'Hern RP, Dowsett M (2008) Letrozole suppresses plasma estradiol and estrone sulphate more completely than anastrozole in postmenopausal women with breast cancer. J Clin Oncol 26: 1671-1676.

Duggan C, Irwin ML, Xiao L, Henderson KD, Smith AW, Baumgartner RN, Baumgartner KB, Bernstein L, Ballard-Barbash R, McTiernan A (2011) Associations of insulin resistance and adiponectin with mortality in women with breast cancer. J Clin Oncol 29: 32-39.

Edman CD, Aiman EJ, Porter JC, MacDonald P (1978) Identification of the estrogen product of extraglandular aromatization of plasma androstenedione. Am J Obstet Gynecol 130: 439-447.

Edman CD, MacDonald PC (1978) Effect of obesity on conversion of plasma androstenedione to estrone in ovulatory and anovulator young women. Am J Obstet Gynecol 130: 456-461.

Eliassen AH, Colditz GA, Rosner B, Willett WC, Hankinson SE (2006) Adult weight change and risk of postmenopausal breast cancer. JAMA 296: 193-201.

Ewertz M, Gray KP, Regan MM, Ejlertsen B, Price KN, Thürlimann B, Bonnefoi H, Forbes JF, Paridaens RJ, Rabaglio M, Gelber RD, Colleoni M, Láng I, Smith IE, Coates AS, Goldhirsch A, Mouridsen HT (2012) Obesity and risk of recurrence or death after adjuvant endocrine therapy with letrozole or tamoxifen in the breast international group 1-98 trial. J Clin Oncol 30: 3967-3975.

Ewertz M, Jensen MB, Gunnarsdottir KA, Højris I, Jakobsen EH, Nielsen D, Stenbygaard LE, Tange UB, Cold S (2011) Effect of obesity on prognosis after early-stage breast cancer. J Clin Oncol 29: 25-31.

Folkerd EJ, Dixon JM, Renshaw L, A'Hern RP, Dowsett M (2012) Suppression of plasma estrogen levels by letrozole and anastrozole is related to body mass index in patients with breast cancer. J Clin Oncol 30: $2977-2980$.

Geisler J, Haynes B, Anker G, Dowsett M, Lønning PE (2002) Influence of letrozole (Femara) and anastrozole (Arimidex) on total body aromatization and plasma estrogen levels in postmenopausal breast cancer patients evaluated in a randomized, cross-over-designed study. J Clin Oncol 20: 751-757.

Geisler J, Helle H, Ekse D, Duong NK, Evans DB, Nordbø Y, Aas T, Lønning PE (2008) Letrozole is superior to anastrozole in suppressing breast cancer tissue and plasma estrogen levels. Clin Cancer Res 14: 6330-6335.

Goodwin PJ, Ennis M, Pritchard KI, Trudeau ME, Koo J, Madarnas Y, Hartwick W, Hoffman B, Hood N (2002) Fasting insulin and outcome in early-stage breast cancer: Results of a prospective cohort study. J Clin Oncol 20: 42-51.

Hornung RW, Reed LD (1990) Estimation of average concentration in the presence of non detectable values. Appl Occup Environ Hyg 5: 46-51.

Irwin ML, Duggan C, Wang CY, Smith AW, McTiernan A, Baumgartner RN, Baumgartner KB, Bernstein L, Ballard-Barbash R (2011) Fasting C-peptide levels and death resulting from all causes and breast cancer: The health, eating, activity, and lifestyle study. J Clin Oncol 29: 47-53.

Judd HL, Judd GE, Lucas WE, Yen SS (1974) Endocrine function of the postmenopausal ovary: concentration of androgens and estrogens in ovarian and peripheral vein blood. J Clin Endocrinol Metab 39: 1020-1024.

Key TJ, Appleby PN, Reeves GK, Roddam AW, Helzlsouer KJ, Alberg AJ, Rollison DE, Dorgan JF, Brinton LA, Overvad K, Kaaks R, Trichopoulou A, Clavel-Chapelon F, Panico S, Duell EJ, Peeters PH, Rinaldi S, Fentiman IS, Dowsett M, Manjer J, Lenner P, Hallmans G, Baglietto L, English DR, Giles GG, Hopper JL, Severi G, Morris HA, Hankinson SE, Tworoger SS, Koenig K, Zeleniuch-Jacquotte A, Arslan AA, Toniolo P, Shore RE, Krogh V, Micheli A, Berrino F, Barrett-Connor E, Laughlin GA, Kabuto M, Akiba S, Stevens RG, Neriishi K, Land CE, Cauley JA, Lui LY, Cummings SR, Gunter MJ, Rohan TE, Strickler HD. Endogenous Hormones Breast Cancer Collaborative Group (2011) Circulating sex hormones and breast cancer risk factors in postmenopausal women: reanalysis of 13 studies. $\mathrm{Br} J$ Cancer 105: 709-722.

Ligibel JA, Winer EP (2012) Aromatase inhibition in obese women: how much is enough? J Clin Oncol 34: 2940-2942.

Lønning PE, Ekse D (1995) A sensitive assay for measurement of plasma estrone sulphate in patients on treatment with aromatase inhibitors. J Steroid Biochem Mol Biol 55: 409-412.

Lønning PE, Helle SI, Jonannessen OC, Adlercreutz H, Lien EA, Tally M (1995) Relation between sex hormones, sex hormone binding globulin, insulin like growth factor and insulin growth factorl binding protein in postmenopausal breast cancer patients. Clin Endocrinol 42: 23-30.

Lønning P, Pfister C, Martoni A, Zamagni C (2003) Pharmacokinetics of third-generation aromatase inhibitors. Semin Oncol 30: 23-32.

Lunardi G, Piccioli P, Bruzzi P, Notaro R, Lastraioli S, Serra M, Marroni P, Bighin C, Mansutti M, Puglisi F, Porpiglia M, Ponzone R, Bisagni G, Garrone O, Cavazzini G, Clavarezza M, Del Mastro L (2013) Plasma estrone sulfate concentrations and genetic variation at the CYP19A1 locus in postmenopausal women with early breast cancer treated with letrozole. Breast Cancer Res Treat 137: 167-174.

Michaud LB, Buzdar AU, Rubin S (2002) The efficacy of anastrozole is not dependent upon body mass index (BMI) in post-menopausal women with advanced breast cancer. Proc Am Soc Clin Oncol 21: 55a.

Miller WR (2006) Aromatase and the breast: regulation and clinical aspects. Maturitas 54: 335-341.

Niraula S, Ocana A, Ennis M, Goodwin PJ (2012) Body size and breast cancer prognosis in relation to hormone receptor and menopausal status: a metaanalysis. Breast Cancer Res Treat 134: 769-781.

Pfeiler G, Königsberg R, Fesl C, Mlineritsch B, Stoeger H, Singer CF, Pöstlberger S, Steger GG, Seifert M, Dubsky P, Taucher S, Samonigg H, Bjelic-Radisic V, Greil R, Marth C, Gnant M (2011) Impact of Body Mass Index on the efficacy of endocrine therapy in premenopausal patients with breast cancer: an analysis of prospective ABCSG-12 trial. J Clin Oncol 29: 2653-2659.

Pfeiler G, Königsberg R, Hadji P, Fitzal F, Maroske M, Dressel-Ban G, Zellinger J, Exner R, Seifert M, Singer C, Gnant M, Dubsky P (2013) Impact of body mass index on estradiol depletion by aromatase inhibitors in postmenopausal women with early breast cancer. $\mathrm{Br} J$ Cancer 109: $1522-1527$.

Reeves GK, Pirie K, Beral V, Green J, Spencer E, Bull D (2007) Cancer incidence and mortality in relation to body mass index in the Million Women Study: cohort study. BMJ 335: 1134.

Renehan AG, Frystyk J, Flyvbjerg A (2006) Obesity and cancer risk: the role of the insulin-IGF axis. Trends Endocrinol Metab 17: $328-336$. 
Schmid P, Possinger K, Bohm R (2000) Body mass index as predictive parameter for response and time to progression in advanced breast cancer treated with letrozole or megestrol acetate. Proc Am Soc Clin Oncol 19: 103a.

Sestak I, Distler W, Forbes JF, Dowsett M, Howell A, Cuzick J (2010) Effect of body mass index on recurrences in tamoxifen and anastrozole treated women: an exploratory analysis from the ATAC trial. J Clin Oncol 28: 3411-3415.

Seynaeve C, Hille E, Hasenburg A, Rea D, Markopoulos C, Hozumi Y, Putter H, Nortier H, van Nes J, Dirix L, van de Velde C (2010) The Impact of Body Mass Index (BMI) on the efficacy of adjuvant endocrine therapy in postmenopausal hormone sensitive breast cancer (BC) patients; Exploratory Analysis from the TEAM Study. Cancer Res 70(Suppl 24): S2-S3.

Sparano JA, Wang M, Zhao F, Stearns V, Martino S, Ligibel JA, Perez EA, Saphner T, Wolff AC, Sledge Jr GW, Wood WC, Fetting J, Davidson NE (2012) Obesity at diagnosis in associated with inferior outcomes in hormone receptor-positive operable breast cancer. Cancer 118: 5937-5946.
Vrieling A, Buck K, Kaaks R, Chang-Claude J (2010) Adult weight gain in relation to breast cancer risk by estrogen and progesterone receptor status: a meta-analysis. Breast Cancer Res Treat 123: 641-649.

Wolters R, Schwentner L, Regierer A, Wischnewsky M, Kreienberg R, Wöckel A. (2012) Endocrine therapy in obese patients with primary breast cancer: another piece of evidence in an unfinished puzzle. Breast Cancer Res Treat 131: 925-931.

Zhang Y, Daquinag AC, Amaya-Manzanares F, Sirin O, Tseng C, Kolonin MG (2012) Stromal progenitor cells from endogenous adipose tissue contribute to pericytes and adipocytes that populate the tumor microenvironment. Cancer Res 72: 5198-5208.

This work is published under the standard license to publish agreement. After 12 months the work will become freely available and the license terms will switch to a Creative Commons AttributionNonCommercial-Share Alike 3.0 Unported License. 